\title{
On Commercial Rumours Governance And Government Responsibility
}

\author{
Suisheng Zhao \\ Xijing University, Department of Ideological and Political Education \\ No1 Xijing Road, Chang'an, Xi'an, Shaanxi 710123 \\ zhaosuisheng@126.com
}

Keywords: Market economy; Commercial Rumours;Commercial culture;Government responsibility

\begin{abstract}
Commercial rumors is the product of the market economy. With the establishment of market economy system in China, commercial rumors become a new kind of social effects of pollution. Commercial rumors brings serious harm to the economic and social development.Strengthen research rumours governance, is great significance for the healthy development of the socialist market economy. The government should not be a spectator in the management of commercial rumors. The government uses the administrative means and legal means to deal with the commercial rumors.
\end{abstract}

\section{The Harm of Commercial Rumors}

Commercial Rumor Is The Product of Market Economy. Commercial rumors are market competitors in order to change the pattern of market competition, deliberately fabricating illegal means to spread false information, slander each other enterprise or product reputation, Destroy the competition behavior.

Commercial rumor is the product of market economy. Along with the deepening of the reform of China's market economy, enterprises become the main body of the market and independent legal entities. The market competition mechanism between various enterprises has been fully formed, and the commercial rumor, which is a bad commercial culture, has begun to emerge and become a social nuisance we have to face.

The market economy system brings enormous vitality to the economic development, and is due to the equal competition mechanism. Under the condition of market economy, enterprise operators can only survive and develop in the fierce market competition, only by constantly improving the quality of products, improving after-sales service, improving the technical content and reducing the cost of products. But the market always has some enterprises, in order to defeat the competitor or to seize the market, uses the mean method to manufacture the commercial rumor intentionally, cheat the consumer.The target of commercial rumor is the excellent enterprise and quality product which have high quality of product or good after-sale service and higher market share. Companies and products without market competitiveness will not be the targets of commercial rumors. Therefore, commercial rumors have always been the vicious killers of famous brand products.

The Serious Harm of Commercial Rumors. Commercial rumor seriously harms the development of economy and society: First, it uses unfair competition to destroy the environment of fair competition in the market and interferes with the market order. Second, it contributes to the development of bad business ethics and culture, and has a huge impact on the socialist morality. It runs counter to the social, moral goals of justice, the rule of law, honesty and friendliness. Third, it contributed to the mercenary egoism, money worship decadent ideas spread, challenge the bottom line of social equity and justice. Fourth, it violates the legitimate rights and interests of honest and law-abiding enterprises and leads to adverse effect which undermines the healthy development of the social economy, Fifth, it kills excellent enterprises and high-quality products, not only undermines the interests of competitors, but also undermines the rights and interests of consumers. 


\section{The Characteristics of Commercial Rumors}

Commercial Rumours Are False. There is no basic factual basis for the information spread by commercial rumors. It is entirely fabricated by gossip.

Commercial Rumors Are Covert. Commercial rumor fabricator often hide in the dark and are hard to verify at the source.

Commercial Rumors Are Highly Destructive. In the market environment of encouraging competition, once the enterprise is attacked by commercial rumor, the light will damage the image of the victim enterprise, and the sale of the product will decline sharply, and the heavy case will lead to the bankruptcy of the enterprise.

The commercial rumor Is Characterized by Sensationalism. Makers of commercial rumors pay great attention to capture the public's curiosity, false information fabricated often droller, it can attract people's attention, so as to achieve the effect of the spread spread like wildfire.

The Speed of Propagation Is Fast. In the traditional media era, strict media "gatekeeper" system, so that some vulgar malicious business rumors can not spread through the media. But in today's Internet age, everyone has the "microphone", so that commercial rumors have a fast spread speed, expanding the scope of communication, more powerful new features. The victim enterprise often does not have the time to respond, the situation has expanded to the uncontrollable situation.

It's Difficult to Protect Rights For Commercial Rumors Victims. Commercial rumors hide in the dark, so it is difficult for victims to maintain their legitimate rights and interests through legal channels, so that the infringer receive difficult to be punished.

It's Difficult to Eliminate The Adverse Effect. Many commercial rumors are absurd, and victims are often concerned that the process of clarifying rumors may spread rumors. Even if the enterprise has not been completely knocked down, but the corporate image has been greatly damaged, it is very difficult to completely eliminate its adverse effects.

\section{Classified Analysis of Commercial Rumors}

Targeted Commercial Rumors And Pan Targeted Commercial Rumors. Targeted business rumors are targeted, with rumours targeting specific businesses and products of a specific brand.This kind of commercial rumors mastermind behind is generally the same industry market participants. The purpose is to destroy rival products, enterprise and product image, to change the pattern of market competition, enterprises improve their products, market share, or to other retaliatory purposes. In mid 90s, Xi'an famous product "Hans" brand of beer was suddenly shot hit rumors in the season. The market is rumoured to have found dead body in the fermenting pots of the Hans brewery in Xi'an. This is typical of targeted business rumors. This ridiculous rumor made Hans beer pay a heavy price, and its good market reputation was destroyed. Hans's beer, which nobody bought in the twinkling of an eye, was eventually driven out of the market.

Pan targeted commercial rumors is no specific goal of trade rumors attack object, this kind of rumor makers generally no malicious, often because the media launched an article or made a speech, The hearsay information as a scientific conclusion spread, has aroused strong repercussions. A few years ago, a newspaper article on bananas containing carcinogenic substances, through a large number of media reprinted, so that consumers talk about banana discoloration, resulting hundreds of thousands of banana farmers suffered heavy losses in Guangdong, Guangxi, Hainan provinces.

Malicious Commercial Rumors And Non Malicious Commercial Rumors. The difference between the two lies in whether the commercial rumor schemer and the spreader have framed or attacked the subjective intention of the enterprise. Clearly, targeted commercial rumors are typical of malicious business rumors, while pan targeted commercial rumors are generally non malicious business rumors.

Self Commercial Rumor. The characteristic of this kind of commercial rumor is that the rumor is aimed at its own enterprise, and the purpose is to gain profits. In mid 90s, some rural areas in southern Anhui province blew up a wave of panic buying red umbrella. Originally, there is a gear production of a large number of red umbrella caused by slow-moving. The director who came up 
with an idea: to spread rumors in the community, said the recent natural disasters, but as long as a red umbrella can avoid calamity. The rumor spread quickly, and in less than two months the company had sold out its red umbrella. Although this kind of commercial rumor has not harmed to other enterprises, but belongs to the fraudulent sale, should be condemned by the public opinion and the suppression.

\section{Government Responsibility in Commercial Rumor Governance}

In the management of commercial rumors, the government should not play an outsider role, but should act as a positive. At present, the reality of our country is that the government is not active. On the one hand, it is difficult for the injured enterprises to ask for help from the law, and they are not accustomed to seeking government help. They can not see the government's responsibility to maintain order in the market. On the other hand, the government generally takes a "stand by" attitude towards commercial rumors. The government believes that commercial rumors are market competition phenomena and contradictions among enterprises, and there is no need for the government to come forward.

The government's ambiguous attitude to commercial rumours is quite wrong. In commercial rumor governance, the government should not be an onlooker or an outsider, but should be a responsible administrator.

Standing In The Height of Ruling The Country According to Law, The Government Has The Rresponsibility to Actively Manage Commercial Rumors. Commercial rumors makers who challenge the law, undermine the rule of law, and abuse the interests of others by illegal means should be punished by the government.

From The Angle of Maintaining The Order of Fair Competition in The Market, The Government Should Actively Control Commercial Rumors. The government is the night watchman of fair order and social justice in the market. Commercial rumor is a malignant tumor of the market, which seriously destroys the game rules of free competition and fair trade in the market, and hinders the healthy development of the socialist market economy. This kind of ugly phenomenon is not eliminated, and the market can not achieve fair and just.

Standing On The High Level of Protecting National Interests And National Brands, The Ggovernt Should Actively Control Commercial Rumors. The targets of cmenommercial rumors are often excellent enterprises and best-selling products with high market popularity. Famous brand is not only the huge intangible asset of the enterprise, but also the precious wealth of the country and the reflection of the national economic strength. If China's economy wants to become an economic power and maintain its competitiveness in the process of economic globalization, it must have a world class of famous brand products. Famous brands need to grow up in the baptism of fierce market competition, and they also need to grow and develop in the good market environment which the State takes good care of.

In View of The Constitutional Spirit of Protecting The Collective And Lawful Property of Citizens, The Government Should Actively Control Commercial Rumors. If the commercial rumor strikes the private organization, it is a violation of the legal property of its owner, and if it infringes on the state-owned enterprise, it infringes upon the property interests of all citizens. China's constitution stipulates that the state protects the lawful property of collectives and citizens without being infringed. It is a government dereliction of duty to turn a blind eye to blatant commercial crimes against other people's property.

In the View of Strengthening Socialist Spiritual Civilization, The Government Should Actively Control Commercial Rumors. The commercial rumor hurts the law-abiding enterprises, and the illegal businessmen benefit, destroy the social public order and morals, and trample on the socialist core value system. In order to maintain good social ethics, it is the government's duty to say "no" to commercial rumors". 


\section{The Main Ways And Means For Government to Control Commercial Rumors}

Administrative Means. First of all, relevant government departments should carry out the business ethics culture education regularly, enhance the public opinion positive guidance, and strive to create the integrity of law-abiding business, fair competition in the commercial and cultural atmosphere, improve the consciousness of the commercial market participants boycott rumors. Secondly, the government, business administration and other related departments should strengthen the monitoring of the market environment, and maintain the good market environment and maintain a fair, just and competitive order as their duties. Once signs of commercial rumors are found, the government should know the facts in a timely manner, use the credibility of the government to clarify the facts, and take the initiative to help victims of enterprises rumor, trying to help victims of enterprises to reverse the passive situation. Thirdly, in the face of commercial rumors, the government should start the investigation procedures in a timely manner and exert the necessary pressure on suspected rumor mongers. The government should dare to crack down on commercial rumor makers, so as to play a warning role to the parties involved in the market.

Legal Means. Market economy is the rule of law economy, and the government must crack down on commercial rumors in accordance with the law, and play the deterrent role of the law. China's<Anti Unfair Competition Law> explicitly includes commercial rumors in unfair competition, which is stipulated in the fourteenth article of this law: "Operators shall not fabricate or disseminate false facts to impair the commercial reputation and reputation of competitors." The third article provides clear responsibilities for the government to administer the market in accordance with the law: The people's governments at various levels shall take measures to stop unfair competition and create a favorable environment and conditions for fair competition." In addition, China's criminal law and the provisions of libel, by attacking the entrepreneur to attempt to discredit the enterprise or product business rumors, can also be in accordance with the criminal law offences of defamation. Only by increasing the legal crackdown can we effectively curb the spread of commercial rumors.

\section{Reference}

[1] Liu Yongchun. Business Rumors: Invisible Killers. [J] Modern Business, 1995. 8.

[2] Yan Feng. When Business Rumors Are Coming, [N] Today News, 2003-01-09

[3] Bing Ling. Commercial Market Rumors: Turbid Water. J China Administration, 1995.10.

[4] An Ping. Internet Self-regulation in The UK. [J] Today Media, 2011.9.

[5] Ye Lang. Commercial Rumor: In The Modern Economic Life Freak. [J] Gongxiaoyuan Friends, 1995.2.

Author introduction:

Suisheng Zhao, male, Han nationality, born in October 1953, of Shaanxi Province, Qingjian County, Master's degree,ideological Department of Xijing University professor. Main research interests: Marx's theory .

Address: 710123 Shaanxi Xi'an city Changan District Xijing Road No. 1, ideological Department of Xijing University.

TEL. 13060355207 E-MAIL: zhaosuisheng@126.com 